\title{
Cultura midiática e religião: Contribuições para uma hermenêutica prospectiva
}

\author{
Abimar Oliveira de Moraes
}

Queremos refletir, nesta comunicação ${ }^{1}$, sobre a influência da Comunicação Social na cultura contemporânea; principalmente no que diz respeito à "nova" compreensão religiosa que surge neste contexto. Cultivar valores, símbolos e crenças é uma das características da Comunicação Social; por isso, vemos a atual experiência religiosa deslocar-se para uma cultura midiática ${ }^{2}$.

Não iremos discutir a questão ética, as implicações morais, a deontologia de tal fato, mas simplesmente, tentar compreender um pouco melhor como esta nova cultura global da Comunicação Social influencia, ajuda e põe obstáculos à experiência religiosa contemporânea. E, principalmente, tentar refletir sobre possíveis passos a serem dados por quem se interessa academicamente por esse tema.

\footnotetext{
${ }^{1}$ Esta comunicação foi originalmente apresentada no II Congresso da Associação Nacional de Pós-graduação e Pesquisa em Teologia e Ciências da Religião (ANPTECRE), em Belo Horizonte, que tinha por tema: Fenomenologia e Hermenêutica do Religioso. O texto aqui apresentado é uma síntese dos principais aspectos levantados pelo autor.

${ }^{2}$ J.B. CARDOSO - R.E. dos SANTOS - H. VARGAS, Inovações na linguagem e na cultura midiática, in R.E. dos SANTOS - H. VARGAS, J.B. CARDOSO (Orgs.), Mutações da cultura midiática, São Paulo, 2009, 28-35.
} 


\section{Uma "provocação herética"}

Quando solicitamos nossas tradições religiosas do mundo ocidental a apresentarem a imagem clássica de Deus, todas, com pequenas variações, dirão que Deus é um espírito onipotente, onisciente, onipresente e misterioso. Em termos gerais, tal descrição de Deus aplica-se também a mídia: uma segunda divindade, criada pelas mãos humanas ${ }^{3}$.

De fato, Rádio, Televisão, Internet, dentre outras, estão em toda parte. Milhões de pessoas ouvem e cantam as mesmas canções, vivem as mais variadas emoções dos personagens apresentados [e rapidamente eclipsados] pela cultura midiática. Tais semelhanças de experiências e sentimentos são óbvias a todos nós.

A Comunicação Social é onisciente, é fornecedora de conhecimentos, é provocadora de emoções, é fomentadora de uma moral comum. Ela afeta profundamente as atitudes de uma comunidade, as suas estruturas políticas e o seu estado psicológico. Pode alterar o curso de uma guerra, exaltar os humildes e derrubar os poderosos de seus tronos.

A Comunicação Social está em toda parte e em parte alguma, é um espírito que sopra aonde quer, uma entidade incorpórea que não ocupa espaço e, paradoxalmente, ocupa todo o espaço. As "vozes" midiáticas não têm corpo, são invisíveis.

Não precisamos de uma casa especial [com torre e sino] para nos comunicarmos com esse "segundo deus". Ele vem às nossas casas todos os dias, tem seu lugar junto à nossas famílias, nossos trabalhos, nosso lazer.

Esse deus possibilita, até mesmo, que acreditemos naquilo que antes era um exercício de fé: o milagre de falar com uma voz incorpórea e de ouvila, bem ao estilo das teofanias das Escrituras proto e neotestamentárias. Faznos não mais invejarmos, até mesmo, aos grandes santos e santas, únicos [até então] capazes da bilocação.

Apesar de ter sido criado pelos humanos, este deus é livre, tem o poder de agir independentemente, abençoa e amaldiçoa.

É óbvio que esta analogia é restrita, não sendo nossa intenção levá-la aos limites extremos. Com essa "provocação herética" queremos somente introduzir nossa reflexão. Com ironia, desejamos afirmar seriamente que a cultura midiática tem influenciado nossas vidas e modelado nossas crenças tão profundamente quanto qualquer religião.

\footnotetext{
${ }^{3}$ T. SCHWARTZ, Mídia: O Segundo Deus, São Paulo, 1985, 19-23.
} 


\section{Esforço para análise e compreensão}

O ser humano, processualmente, vai desenvolvendo sua racionalidade; seu simbolismo; vai conquistando sua liberdade; experimentando emoções novas; que permitem a criação de uma cultura própria, que é o encontro do complexo relacionamento entre os vários fatores com os quais está em contato ${ }^{4}$.

Já dissemos que cultivar valores, símbolos e crenças é uma das características da Comunicação Social; por isso, podemos afirmar que convivemos com uma cultura midiática.

Por muito tempo, a experiência religiosa foi vivida dentro das dimensões geográficas/familiares ${ }^{5}$. A entronização da "religião", num determinado lugar, correspondia [e ainda corresponde] à formação de novos espaços geográficos. ${ }^{6}$

Contudo, o processo de descristianização no qual nos encontramos, solicita a descoberta de uma dimensão coletiva religiosa, que não corresponde somente àquela geográfica/familiar ${ }^{7}$.

Uma nova dimensão se apresenta a nós. Uma realidade humana que responde às aspirações mais profundas da natureza e permite o surgimento de uma "nova" antropologia ${ }^{8}$ e, consequentemente, uma "nova" religiosidade. Pois o humano se sente ligado ao mundo inteiro. Cada pessoa humana está coligada a todas as outras pela Rádio, pela Televisão, pela Internet e etc.; é aqui que a "nova" religiosidade se situa; neste "novo" contexto que deu aos seres humanos a sua "cidadania planetária".

${ }^{4}$ G. ROCHER, Introduzione alla Sociologia Generale. L'Azione e L'Organizzazione Sociale. Il Cambiamento Sociale, Gallarate (VA), ${ }^{7} 1992,93$.

5 A. JOOS, La sfida comunicativa: formarsi cristianamente comunicando?, in "Presenza Pastorale" 1 (1991) 25.

${ }^{6}$ Exemplo bem claro disso é a ainda vigente definição de paróquia católica dada pelo Código de Direito Canônico (Código de Direito Canônico, São Paulo, ${ }^{2} 1987$, c. 515, § 1).

7 R. WHITE, I mass media e la cultura nel cattolicesimo contemporaneo, in R. LATOURELLE (Ed.), Vaticano II: Bilancio e Prospettive. Venticinque anni dopo (1962-1987). Vol. II, Assisi, 1989, 1555.

${ }^{8}$ A. MORAES, Uma "nova" antropologia na era da Comunicação, in "Communio" 22 (2004) 385-401.

${ }^{9}$ Segundo Nicolaci-da-Costa, diferentemente do que muitos temiam e afirmavam, nos momentos iniciais, a realidade "virtual" não criou um mundo paralelo sem conexão com o mundo "real". Mas os dois mundos acabaram por se tornar duas plataformas de vida em permanente interação (A.M. NICOLACI-DA-COSTA, Internet: uma nova plataforma de vida, in A.M. NICOLACI-DA-COSTA (Org.), Cabeças Digitais. $O$ 
A Comunicação Social não só facilitou e tornou mais agradável a vida humana, mas gerou, em conseqüência da sua rápida difusão, uma mutação cultural substancial tão incisiva que determinou, em todo mundo, a passagem do homo sapiens ao homo comunicans ${ }^{10}$.

Vivemos num tempo marcado pela Comunicação Social. Numa sociedade globalmente complexa, articulada e significativamente em evolução, na qual, porém, não obstante a sua complexidade, podemos individuar elementos que a contra-distinguem de maneira inequívoca e que definem as suas características próprias em relação com os períodos precedentes da sociedade rural e da sociedade industrial ${ }^{11}$.

A difusão da Comunicação Social, gerou toda uma série de mudanças em todos os setores da vida social. Assistimos ao surgimento da "informação-comunicação" como elemento base para a "fruição-gestão" do poder político. O poder econômico apoiou-se sobre uma gestão da Comunicação e das trocas comunicativas. Nem mesmo o setor tecnológico, ficou imune a esta mudança.

A tecnologia foi colocada a serviço da Comunicação Social criando um desenvolvimento das "máquinas" de comunicar que vai avante em ritmo exponencial. As "máquinas" [os Meios de Comunicação Social] tornam-se sempre mais ágeis, mais velozes, os sistemas comunicativos sempre mais complexos, de forma, que é muito difícil acompanhar o ritmo das sempre maiores novidades, nesta área ${ }^{12}$.

A Comunicação Social produz e difunde "informações" em todo o mundo. Portanto, sabemos já que a nova fonte de poder não é mais a posse

cotidiano na era da informação, Rio de Janeiro, 2006, 35). Sá e Andrade acreditam que as fronteiras entre "real" e "virtual" foram borradas. Daí deriva o fascínio por games como o Second Life (S.P. de SÁ - L.A. de ANDRADE, Entretenimento e cibercultura: o que os mundos virtuais Second Life e Stars Wars Galaxies nos ensinam sobre a primeira vida?, in R.E. dos SANTOS - H. VARGAS, J.B. CARDOSO (Orgs.), Mutações da cultura midiática, São Paulo, 2009, 85).

${ }^{10}$ JOOS, La sfida comunicativa, 29.

${ }^{11}$ Para um aprofundamento dos principais elementos dessa sociedade ver, dentre outros: P. ANDERSON, As origens da pós-modernidade, Rio de Janeiro, 1999; Z. BAUMAN, Modernidade líquida, Rio de Janeiro, 2001; E.A. KAPLAN (Org.), $O$ mal-estar no pós-modernismo. Teorias e práticas, Rio de Janeiro, 1993; K. KUMAR, Da sociedade pós-industrial à pós-moderna. Novas teorias sobre o mundo contemporâneo, Rio de Janeiro, 1997.

${ }^{12}$ Por esse motivos, alguns estudos já vem sendo feitos, em busca de uma Nova Ordem Tecnológica (ver: A. BARBOSA FILHO, - C. CASTRO, Comunicação digital. Educação, tecnologia e novos comportamentos, São Paulo, 2008, 13-27). 
da matéria-prima ou a posse da "indústria", mas a posse da "informação"13. $\mathrm{O}$ advento da era da Comunicação Social modificou, de maneira incisiva, o modo de viver de todos, mas, sobretudo, modificou o nosso modo de relacionarmo-nos com o ambiente e entre nós ${ }^{14}$.

Trata-se de uma passagem que tocou todos os aspectos da cultura atual, partindo do ambiente de trabalho, passando pela família, até chegar à religião. Dando vida a uma cultura caracterizada por uma preponderância dos valores do desenvolvimento e do espetáculo, na qual vige a regra de ouro da "publicidade" 15 .

Este processo está em pleno curso e não podemos, nem mesmo, conjeturar de repudiar esta realidade e sair deste universo de referência, pois, isto significaria, a parte renunciar aos aspectos positivos e as vantagens que esta oferece, alienarmo-nos da própria cultura atual e tornarmo-nos "a-sociais".

Nem mesmo é possível refutar alguns aspectos escolhendo entre os que consideramos válidos e os que consideramos danosos, porque tratam-se de aspectos de tal forma inter-conexos entre si que não permitem uma separação senão num nível metodológico.

$\mathrm{Na}$ verdade, conhecemos somente a ponta do iceberg, pois, no momento atual, este fenômeno continua em plena expansão e, portanto, não somos, ainda, capazes de colher plenamente a sua amplitude e de prever as conseqüências, no tempo, sobre os vários planos: psicológico; social; cultural; religioso; teológico; político; ético; econômico; e etc. Até porque o seu ritmo de desenvolvimento aumenta em progressão exponencial e em nível mundial.

Talvez, nesse sentido, estejamos vivendo um "momento liminar": um momento de transição. Momento onde se entrecruzam várias tendências, inúmeros recortes da realidade, novas maneiras de se viver e entender o mundo, a si próprio, a religião, a fé.

Tivemos outras tecnologias que certamente mudaram o ser humano. $\mathrm{O}$ "eu" dessas novas tecnologias é fluído, múltiplo, e até fragmentado. Gerando muitas histórias, muitas religiões, muitas imagens de Deus, não apenas uma.

Se por um lado, essa multiplicidade expande o individualismo, uma sensação de isolamento, ao mesmo tempo permite uma busca incessante de autonomia e da felicidade, aspectos que não podem ser descuidados, pois são tipicamente religiosos.

\footnotetext{
${ }^{13}$ P. BABIN, La Catechesi nell'era della Comunicazione, Leumann (TO), 1989, 1415 .

${ }^{14}$ JOOS, La sfida comunicativa, 9.

${ }^{15}$ BABIN, La Catechesi nell'era della Comunicazione, 16.
} 
É sabido que o sujeito não é algo imutável temporal e espacialmente; o sujeito [inclusive o sujeito religioso] é construído dentro de um específico contexto social-histórico.

No específico ao nosso tema, entendemos que a questão da religião na contemporaneidade está inextricavelmente ligada às transformações na subjetividade causadas em cascata pelo aparecimento da Comunicação Social.

Pensar a religião contemporânea em suas articulações com as profundas transformações propiciadas pelas tecnologias da Comunicação Social disponíveis nos faz falta. E desenvolver um projeto de análise compatível com a complexidade de nosso tema, e com a necessária sofisticação intelectual, é ainda mais indispensável.

Caberia pesquisar cuidadosamente esse universo que se descortina para a Teologia. Existe uma tendência de incorporar e neutralizar rapidamente aquilo que é novo [radicalmente novo] ao já conhecido, perceptível, principalmente nas práticas de "integração" entre religião e mídia a qual temos assistido. $^{16}$

Aquilo que podemos tentar fazer é buscar compreendê-lo, para poder canalizá-lo e endereçá-lo, o quanto possível e em base às nossas forças, positivamente, para utilizar ao máximo as vantagens e tentar limitar ou corrigir os danos. É óbvio que trata-se de uma empresa quase titânica, mas que, não obstante a complexidade e a dificuldade, não podemos abdicar. Pelo contrário, quanto maior é a dificuldade tanto maior deve ser o nosso esforço de compreensão e o nosso empenho.

Diante desse quadro, consideramos que estudar o novo não constitui tarefa fácil, afinal, entrar em contato com questões novas nos obriga a colocar em dúvida nossas "certezas" e repensar nossa realidade. E repensar nossa realidade certamente não é algo cômodo.

É preciso ter a coragem de observar e registrar, num primeiro momento, tudo de novo que acontece diante de nossos olhos. Para fazer partir da observação nossas interpretações que podem criar novas formas de hermenêutica do religioso.

Cremos que enquanto teólogos [ou cientista da religião] é nossa função buscar compreender os impactos que o avanço da cultura midiática terá sobre aquela que é a "matéria-prima" da Teologia: o ser humano.

Novas formas de pensar, agir, sentir e se relacionar com o mundo e com os outros [inclusive com o Outro] são algumas das características do humano que vem emergindo do contato com a cultura midiática.

\footnotetext{
${ }^{16}$ Vejamos, por exemplo, o fenômeno atual dos que chamamos "novos cruzados", presentes nos Meios de Comunicação Social, mas repletos de um discurso pouco apto ao meio e cheio de aspectos apologéticos e moralistas.
} 


\section{3. "Religião tipográfica" e "Religião midiática"}

Diante de tantas mudanças, cunhamos a expressão: "Religião midiática". Uma "religião" que surge em nossos tempos como algo divertido e prazeroso. Em oposição à "religião" tradicional, apontada, por muitos contemporâneos nossos, como "chata", "entediante", "dogmática" que chamaremos de "Religião tipográfica".

A "Religião midiática" é mais veloz, mais ágil, mais prática, mais maleável, mais bonita, mas relativa, mais integrada do que a "tipográfica". Nela não há mais a verdade absoluta, mas sim verdades, na qual a subversão dos parâmetros tradicionais está gerando um conflito de mentalidades ${ }^{17}$.

Anteriormente, dizíamos que o ser humano é construído socialmente, desta forma, defendemos que alterações no cenário social, geralmente resultantes do surgimento de inovações tecnológicas, teriam impacto sobre as mais diversas esferas da vida humana, incluída a religião.

Os impactos mais fundamentais provocados pela comunicação tipográfica só puderam ser sentidos e percebidos num segundo momento, mas estão relacionados à vida mental do ser humano.

Ao elevar o comportamento visual do sentido humano, ao romper o equilíbrio entre os sentidos e, com isso, possibilitar a destribalização do indivíduo, a tipografia impactou de tal forma a subjetividade humana que McLuhan, numa tentativa de classificar o ser humano criado pela imprensa, cunhou a expressão "homem tipográfico" [de onde tiramos a paráfrase] ${ }^{18}$. Este ser humano, segundo ele, teria sido produzido pela mudança na consciência provocada pela tecnologia da palavra impressa.

A ruptura entre a cabeça e o coração, o espírito e o sentimento, resultado do isolamento do aspecto visual da palavra trazido pela tipografia, fez da "Religião tipográfica", uma "religião" extremamente racional. A "Religião tipográfica" absorveu a lógica da tecnologia da imprensa, tendo desenvolvido como principal característica uma compreensão de Deus racional, altamente mecanizada e dogmática.

É importante ressaltar, porém, que, assim como aconteceu com a "Religião tipográfica", que só pode ter suas características devidamente analisadas e descritas por autores que a estudaram muito tempo após o seu surgi-

${ }^{17}$ NICOLACI-DA-COSTA, Internet: uma nova plataforma de vida, 31 . No referido artigo, a autora está falando, especificamente, das conseqüências da experiência da Internet, nas mais distintas áreas da vida humana. Mas acreditamos que seja possível uma aproximação ao aspecto religioso.

${ }^{18}$ M. McLUHAN, A Galáxia de Gutengerg. A formação do homem tipográfico, São Paulo, 1972. 
mento, a "Religião midiática" provavelmente também só poderá ter seu perfil traçado dentro de alguns anos.

No entanto, pensamos ser possível levantar algumas hipóteses a respeito da organização subjetiva dessa "nova" religião.

Talvez pudéssemos supor que a "Religião midiática" venha a apresentar uma maior agilidade como uma de suas características. Não estar tão presa a estruturas hierárquicas rígidas e controladoras. ${ }^{19}$

Mas, cremos ser outra característica da "Religião midiática", contudo, aquela que deverá provocar os maiores impactos sobre a hermenêutica religiosa de nossos tempos: sua maleabilidade.

Se a "Religião tipográfica" se caracterizava por sua visão de Deus linear, mecânica e dogmática, a "Religião midiática" deverá ser identificada exatamente pelo oposto. A flexibilidade deverá ter o poder sobre essa "religião". Maior flexibilidade, maior espontaneidade, menos dogmas: essas poderão ser algumas características fundamentais da "Religião midiática". Certamente, porém, não serão as únicas.

Outras conseqüências, não tão positivas devem ser esperadas. Entre elas, destacamos a impessoalidade. Cremos ser a que merece maior atenção da nossa parte. A "Religião midiática" pode apresentar uma maior frieza no relacionamento interpessoal como uma de suas características.

Contudo, nesse momento, essa não é uma nossa preocupação até porque é impossível afirmar com certeza que qualquer uma das previsões acima confirmar-se-á. Mesmo assim, é fundamental fazê-las. Visto que isso nos leva a refletir acerca das mudanças pelas quais estamos passando, fazendo com que estejamos melhor preparados para entender e lidar com as conseqüências que elas trarão para todos nós.

Se durante muitos anos fomos habitantes da "Galáxia de Gutenberg", hoje, com certeza, estamos vivendo numa outra "Galáxia". Apesar de as conseqüências trazidas pela criação de Gutenberg já serem bem conhecidas por nós, no campo da religião, o mesmo não pode ser dito a respeito dos novos tempos. Não sabemos aonde a religião pode chegar, qual o seu futuro. Cremos, porém, que não devemos esperar de braços cruzados pelos resultados desta nova revolução que estamos vivendo.

\footnotetext{
19 Segundo Schwartz: "podemos afirmar que, em questão de fé, a principal mudança causada pela mídia foi a democratização da religião. Agora todos podem ouvir, observar e comparar os rituais e práticas das diferentes religiões. [...] De repente os outros credos estão à nossa disposição se quisermos explorá-los" (SCHWARTZ, Mídia: $O$ Segundo Deus, 109-110).
} 
Como fizeram outros teólogos e teólogas diante de outras revoluções, cremos que é nosso papel buscar observar e compreender as mudanças que vem acontecendo diariamente a partir da entrada em cena da cultura midiática.

\section{Conclusão}

A questão hoje é grave, pois, a luta dentro dessa cultura fragmentada gerada pela cultura midiática é ferocíssima. As instituições religiosas tradicionais estão perdendo todo o seu poder de controle e de doutrinação [ainda bem]. A "religião" não é mais capaz de "doutrinar". Pois, na nossa frente, opera um grandioso sistema de Comunicação Social que "faz a cabeça" das pessoas. Propondo-lhes padrões culturais, visões de si, dos outros e de Deus.

Nesta realidade difícil, complexa e desafiadora, cabe-nos a tarefa de colher uma série de elementos positivos que são indicativos do fato que as mudanças que estão acontecendo não podem e não devem ser avaliadas com suspeita e prejuízo e que não devem conduzir-nos a perspectivas de tipo apocalíptico e/ou hermético.

É preciso viver sob o sinal do otimismo, sob o sinal da abertura, superando as situações de pessimismo e descrença, confiando nas possibilidades e nas capacidades desse "novo" cenário religioso, renovando a consciência da constante ação de Deus na história humana, mesmo quando não somos capazes de entender o que Ele faz e propõe.

Não se trata de eludir o problema refutando-o ou escondendo-se em visões pessimistas, mas de tomar consciência das problemáticas, de criar estruturas e modalidades operativas eficazes, de abrir novos horizontes. Existem indicadores muito claros que mostram que estamos diante de um terreno fértil sobre o qual devemos refletir e trabalhar.

A realidade contemporânea é, também, aquela da busca sempre mais profunda e plural do transcendente, do retorno do religioso, do despertar do sacro $^{20}$. Ela sente a necessidade de espiritualidade, está em busca desta dimensão, ainda que não consiga individuar os percursos que podem conduzi-la em tal direção, é nesse contexto que busca a "Religião midiática", entendendo que esta faz parte de sua cultura, é uma realidade autêntica e próxima.

Certamente, uma das dimensões em que percebemos mais claramente a crise, a insatisfação, o esgotamento da fase da cultura moderna, é a religiosa. O que parece delinear-se, em vários segmentos, como uma retomada ou uma nova visibilidade do interesse pela religião, pela transcendência [seja a

${ }^{20}$ L. SORAVITO, Risveglio religioso e ritorno al sacro. Criteri per una lettura critico-positiva. Istanze pastorali che ne derivano, in "Credere Oggi" 61 (1991) 105-107. 
denominação "retomada" procedente ou não] consiste num alerta de enorme importância para o fenômeno de certa secularização que é obrigado a confrontar-se, enfim, com a crise de seu modelo. Este aspecto da crise atinge também a experiência religiosa contemporânea adquirindo contornos próprios e originais.

Todos estes desafios colocam a questão religiosa em chave de comunicação. Se a situação cultural com a qual somos chamados a dialogar mudou em relação ao passado, é claro que não podemos continuar utilizando esquemas do passado. É preciso inventar novos esquemas.

Assim, atualmente, somos chamados a um corajoso, profético, humilde e verdadeiro desafio de repensar nossa identidade. A atitude de diálogo nos é exigida pela composição múltipla, plural e diversificada da cultura midiática, tornando-nos capazes de reencontrar sinais e gestos religiosos adequados a esses novos tempos.

Abimar Oliveira de Moraes

Professor de Teologia da PUC-Rio Doutor em Teologia pela Università Pontificia Salesiana de Roma 